\title{
Affective Circuitry and Risk for Alcoholism in Late Adolescence: Differences in Frontostriatal Responses Between Vulnerable and Resilient Children of Alcoholic Parents
}

\author{
Mary M. Heitzeg, Joel T. Nigg, Wai-Ying Wendy Yau, Jon-Kar Zubieta, \\ and Robert A. Zucker
}

\begin{abstract}
Background: Children of alcoholics (COAs) are at elevated risk for alcohol use disorders (AUD), yet not all COAs will develop AUD. The 2 primary aims of this study were to identify neural activation mechanisms that may mark protection or vulnerability to AUD in COAs and to map the same activation patterns in relation to risk behavior (externalizing or internalizing behavior).

Methods: Twenty-two adolescent COAs were recruited from an ongoing community longitudinal study of alcoholic and matched control families. They were categorized as either vulnerable $(n=11)$ or resilient $(n=11)$ based on the level of problem drinking over the course of adolescence. Six other adolescents with no parental history of alcoholism, and no evidence of their own problem drinking were recruited from the same study and labeled as low-risk controls. Valenced words were presented to the participants in a passive viewing task during functional magnetic resonance imaging. Activation to negative versus neutral words and positive versus neutral words were compared between groups. Behavior problems were assessed with the Youth Self-Report (YSR).

Results: The resilient COA group had more activation of the orbital frontal gyrus (OFG), bilaterally, and left insula/putamen than the control and vulnerable groups, in response to emotional stimuli. In contrast, the vulnerable group had more activation of the dorsomedial prefrontal cortex and less activation of the ventral striatum and extended amygdala, bilaterally, to emotional stimuli than the control and resilient groups. The vulnerable group had more externalizing behaviors which correlated with increased dorsomedial prefrontal activation and decreased ventral striatal and extended amygdala activation.

Conclusions: These results are consistent with dissociable patterns of neural activation underlying risk and resiliency in COAs. We propose that the pattern observed in the resilient COAs represents an active emotional monitoring function, which may be a protective factor in this group. On the other hand, the vulnerable group displayed a pattern consistent with active suppression of affective responses, perhaps resulting in the inability to engage adaptively with emotional stimuli.

Key Words: Vulnerability, Resiliency, Ventral Striatum, Prefrontal Cortex, Orbitofrontal Cortex.
\end{abstract}

$\mathrm{O}$ NE OF THE most compelling, still unresolved issues in alcoholism risk research today is that of individual differences: What causes some individuals to become alcoholic and not others? Individual differences in vulnerability involve interactions among genetic, neurobiological, and environmen-

From the Department of Psychiatry, (MMH, WYWY, JKZ, $R A Z)$, The University of Michigan, Ann Arbor, Michigan; and Department of Psychology (JTN), Michigan State University, Lansing, Michigan.

Received for publication May 1, 2007; accepted September 25, 2007.

Reprint requests: Mary M. Heitzeg, PhD, Department of Psychiatry, The University of Michigan, 205 Zina Pitcher Place, Ann Arbor, MI 48109-0720; Fax: 734-647-4130; E-mail: mheitzeg@umich.edu

Copyright $(2) 2008$ by the Research Society on Alcoholism.

DOI: $10.1111 / j .1530-0277.2007 .00605 . x$ tal factors over a significant portion of the life course (National Institute on Alcohol Abuse and Alcoholism, 2000; Zucker, 2006). It is well known that parental alcoholism raises risk for offspring alcoholism (Caspi et al., 1996; National Institute on Alcohol Abuse and Alcoholism, 2000; Russell, 1990) and that genetic influences account for 40 to $60 \%$ of the variance in alcoholism risk (e.g., Heath, 1995; Heath et al., 1997; Kendler et al., 1994). However, the remaining variance is not entirely accounted for by shared family environment (Jacob et al., 2001).

Some of this genetic risk is likely mediated through intermediate behavioral traits, such as behavioral undercontrol/externalization and emotional dysregulation/ internalization (Caspi et al., 1996; Chassin and Ritter, 2001; Cloninger et al., 1988; Zucker, 1994; Zucker et al., 1995). Externalizing behavior problems are elevated in children of 
alcoholic parents (COAs) (Slutske et al., 2002; Wong et al., 1999) and predict later problem alcohol involvement (Sher, 1993; Zucker, 2006). Among adolescents, measures of behavioral undercontrol have been correlated with early age of first use (McGue et al., 2001), greater use (Clark et al., 1999; Mason and Windle, 2002; White et al., 2001; Wills et al., 1996), accelerated alcohol involvement (Clark et al., 2005) and alcohol dependence (Rohde et al., 1996). COAs are also at increased risk for internalizing symptoms (e.g., negative emotion, behavioral inhibition) (Chassin et al., 1993) and measures of negative affectivity have been correlated with adolescent alcohol use (Colder and Chassin, 1993; White et al., 2001) and dependence (Rohde et al., 1996).

With regard to the neural level of analysis of these vulnerabilities, poor regulation of behavior and propensity to negative affect appear to involve closely related yet partially distinct neural circuitry. Numerous neuroimaging studies have shown that ventral anterior cingulate, prefrontal and insular cortices, amygdala and ventral striatum are involved in affective experience and regulation (see review in Phan et al., 2002). Control circuitry - that is, circuitry involved in regulating or suppressing reflexive behavior or cued information -includes portions of the prefrontal and posterior parietal cortices, basal ganglia and thalamus (Aron and Poldrack, 2005; Aron et al., 2003a,b; Casey et al., 1997, 2002). The model guiding our work supposes that subcortical aspects of these circuits (e.g., amygdala, ventral striatum) are related to emotional response (i.e., bottom up responding to stimulus), whereas prefrontal aspects of these circuits are involved in the dynamic regulation of affective responses and motivated behavior (e.g., Hariri et al., 2000, 2002; Nigg and Casey, 2005).

The above circuitry is also closely related to the circuitry involved in reward responsivity, salience attribution, and motivated behavior (Hyman and Malenka, 2001; Koob, 2003; Nestler, 1999). This circuitry, also thought to be relevant to addiction propensity, includes the ventral striatum, amygdala, areas of the prefrontal cortex, and the insular cortex (e.g., Kalivas and Stewart, 1991; Koob, 1999; Naqvi et al., 2007; Volkow et al., 2004). Variation in functioning of these related circuits may contribute to vulnerability or resilience in youth at risk.

Although structural (De Bellis et al., 2000; Medina et al., 2007; Nagel et al., 2005) and functional (Brown and Tapert, 2004; Tapert et al., 2001) differences in this circuitry have been found in adolescents with alcohol use disorders (AUDs) compared with controls, some of these alterations are likely to be caused by, rather than contributing to, alcoholism. On the other hand, some differences between alcohol abusers and control samples may precede alcoholism onset and thus constitute markers of precursive risk. After all, behavioral and affective markers early in life can predict later alcoholism (Caspi et al., 1996; Mayzer et al., 2001). Thus, it is reasonable to hypothesize that prealcoholic differences in the functioning of relevant neural systems will be related to risk for alcoholism.
To date, only a few imaging studies have attempted to address this question. Findings suggest that risk for alcoholism may be associated with smaller amygdala volume (Hill et al., 2001) and decreased amygdala activation to fearful faces (Glahn et al., 2007). However, those studies were conducted in young adults (average ages $>20$ years) who were not problem drinkers. Yet alcoholics often start problem drinking before that age (Grant and Dawson, 1997), so the individuals in these studies may have been selected for their resiliency rather than their vulnerability. That is, although they were selected based on family history to represent a vulnerable population, the fact that they are in their early 20 s and not displaying alcohol problems may be indicative of some protective factor at work. In a functional magnetic resonance imaging (fMRI) study involving 12 to 14-year-old COAs, decreased activation in the left middle frontal gyrus was observed during response inhibition when compared with non-COAs (Schweinsburg et al., 2004). Interpretation of these findings as representing a neural marker of vulnerability remains tentative, however, until follow-up assessments regarding progression to AUD later in life become available.

Here, we attempt to address these limitations with a preliminary study of neural correlates of vulnerability and resiliency in adolescents selected from an on-going longitudinal study of families with parental alcoholism, along with a contrast sample of nonalcoholic families (Zucker et al., 2000). Two questions guided the present study. The first was whether differences in brain response to emotional stimuli could be identified between adolescent COAs who are showing signs of risky alcohol use (who we term "vulnerable") and COAs who are not displaying risky alcohol use (who we term "resilient"). Both groups begin with possible constitutional risk. However, the former group is at high risk for progression into AUD whereas the latter either did not inherit a risky phenotype from their alcoholic parent, or else carried protective factors. We were interested in neural signatures of such factors. A control group of adolescents with no alcoholic parent (and no risky alcohol use) was used to investigate the differences between these 2 possibilities. Differences in brain activation were first identified between the $2 \mathrm{COA}$ groups (with and without risky alcohol use). Next, activation in these regions was compared with that of the nonCOA control group. If the activation in the non-risky COAs differed from controls, but activation in the risky COAs did not, a resiliency mechanism would be supported. If the activation in the risky COA group differed from controls as well as the nonrisky COAs, the presence of vulnerability elements in the neural regions involved would be supported.

Functional imaging was conducted during the passive viewing of positive, negative, and neutral words. Valenced words have been shown to activate the inferior frontal, middle frontal and orbitofrontal cortices, cingulate gyrus, ventral striatum, amygdala, and hippocampus (Epstein et al., 2006; 
Kensinger and Schacter, 2006; Kuchinke et al., 2005; Maddock et al., 2003). Differences were expected in the brain regions involved in emotion and motivation - particularly the amygdala, ventral striatum and regions of the prefrontal cortex-between COAs with high and low risky alcohol involvement. We considered that vulnerability might take the form either of underactivation of affective responding (as in an antisocial-psychopathic route, Blair et al., 2006), or a convergence of over-activation of affect and under-activation of top down cortical regions, as in a dysregulated pathway.

The second aim was to determine whether externalizing and internalizing behavioral traits (1) differed between the COAs with high versus low risky alcohol involvement and (2) if so, were related to brain activation. Given the close association of externalizing behaviors and AUD, we expected higher externalizing behavior in the COAs with high risky alcohol involvement, consistent with vulnerability to an AUD outcome. We further expected externalizing scores to be related to similar functional brain differences as vulnerability to AUD.

\section{METHODS AND MATERIALS}

\section{Participants}

Participants were 28 right-handed adolescents (15 males, 13 females), aged 16 to 20 years (mean $17.8 \pm 1.3$ ). These adolescents were recruited from families in an ongoing, prospective community study of families with high levels of parental alcoholism, along with a contrast sample of nonalcoholic families drawn from the same neighborhoods (Zucker et al., 2000). Longitudinal Study families in which the target child displayed evidence of fetal alcohol effects were excluded. Exclusionary criteria for the adolescent subjects in the present study were any neurological, acute, uncorrected or chronic medical illness; any current or recent (within 6 months) treatment with centrally active medications, including sedative hypnotics; and a history of psychosis or schizophrenia in first-degree relatives. In addition, the presence of an Axis I psychiatric or developmental disorder was exclusionary except in the case of conduct disorders, attention deficit disorder, or SUD. These latter Axis I disorders were allowed as their exclusion would preferentially eliminate participants at highest risk for SUD. Two sources were used to determine diagnosis. First, as part of the on-going longitudinal study, each participant was assessed with the Diagnostic Interview Schedule-Child (Costello et al., 1984) every 3 years starting at ages 9 to 11 years. Second, during the screening process as part of recruitment for the present study, each participant was asked whether they had been diagnosed with any psychiatric illness.

All participants gave written informed consent after explanation of the experimental protocol, as approved by the University of Michigan Institutional Review Board. Subjects under the age of 18 years signed their assent to participate in the study and at least 1 parent gave written informed consent.

Of the 28 participants, 22 were $\mathrm{COA}$, that is, they were from families in which at least the father had a lifetime diagnosis of AUD, based on DSM IV criteria; mother diagnosis was free to vary. COAs were further categorized as either vulnerable $(n=11)$ or resilient $(n=11)$ based on a composite problem drinking index described below. The remaining 6 participants were low-risk controls with no parental history of AUD in either parent, and no evidence of their own problem drinking. The characteristics of each group are summarized in Table 1. There were no differences in the age of males and females overall or within each group $(p>.05)$.

\section{Measures}

AUD Risk. The AUD vulnerability/resilience status was determined by combining 3 variables in a composite score: (1) whether there was early-onset drinking, defined as having more than a sip of alcohol by age 14 (yes $=1$; no $=0$ ); (2) whether ever drunk by the time of the most recent assessment, which occurred when participants were between 15 and 17 years of age (yes $=1$; no $=0$ ); and (3) number of different self-reported drinking problems (out of a possible 27; measure described below) between 11 and 17 years of age (based on a median split: 0 to 5.6 problems $=0$, greater than 5.6 problems $=1)$. Using this method, each subject received a score ranging from 0 (no early onset, never drunk, and 5.6 or fewer drinking-problems between ages 11 to 17 years) to 3 (early onset, have been drunk, and greater than 5.6 drinking problems between ages 11 to 17 years). Those who scored 2 or 3 were considered vulnerable; while those who scored 0 or 1 were considered resilient (that is, they carried putative COA risk but did not express it). A third group, termed low risk, involved youth who were not COA and did not display problem drinking behavior (also see Nigg et al., 2007 and Zucker et al., 2003).

Number of drinking-related problems was assessed using the selfreport Drinking and Drug History Form for Children, a children's version of the Drinking and Drug History Form for Adults (Zucker and Fitzgerald, 1994; Zucker et al., 1990). Onset of use items were elaborated from the adult form to be relevant for children and youth; otherwise, the measure covers the same substantive content-quantity, frequency, and variability of alcohol consumption; frequency of other drug use; and questions regarding consequences and problems related to alcohol use as perceived or experienced by children (a separate section inquires about drug problems but is not utilized here). The measure was administered yearly between the ages of 11 and 17, so responses were relatively contemporaneous to the drinking experience. For the present study, the number of different drinking-related problems out of a possible 27 (e.g., got into trouble with police because of drinking, driven a car after having a good bit to drink) ever reported by the subject between the ages of 11 and 17 years was the score.

Externalizing Behavior Problems. Behavior problems were assessed with the Youth Self-Report (YSR). The YSR, developed by Achenbach (1991), was completed by each participant when they were between 15 and 17 years old. It provides an assessment of the respondent's social and emotional functioning. The instrument has been normed on a nationally representative community sample of adolescents and yields standardized scores on 8 narrow band subscales (withdrawn, somatic complaints, anxious/depressed, social problems, thought problems, attention problems, delinquent behavior, aggressive behavior), 2 broad band subscales (externalizing and internalizing behavior) and a total behavior problems score (Table 1).

fMRI Task. Words with positive, negative, or neutral valence were viewed in a blocked design. Subjects were instructed to silently read each word and press a switch if they understood the word. Words were selected from the Affective Norms for English Words (ANEW) list, which provides a set of normative emotional ratings for a large number of words in the English language (Bradley and Lang, 1999). The words in the ANEW list were rated on the dimensions of valence and arousal on a scale of 1 (negative valence; low arousal) to 9 (positive valence; high arousal). For the present study, we chose negative words with an average valence rating of less than 3 , neutral words with valence ratings between 4.5 and 5.5 and positive words with a valence rating greater than 7 . Arousal ratings were greater than 5 for positive and negative words and greater than 2 for neutral words. The average arousal ratings for the final lists of positive and negative words did not differ from one another $(6.1 \pm 0.6$ 
Table 1. Subject Characteristics for Control, Resilient, and Vulnerable Groups

\begin{tabular}{|c|c|c|c|c|c|c|}
\hline & \multirow{2}{*}{$\begin{array}{l}\text { Control } \\
(n=6)\end{array}$} & \multirow{2}{*}{$\begin{array}{l}\text { Resilient } \\
(n=11)\end{array}$} & \multirow{2}{*}{$\begin{array}{c}\text { Vulnerable } \\
\qquad(n=11)\end{array}$} & \multicolumn{3}{|c|}{ Resilient versus vulnerable } \\
\hline & & & & $\chi^{2}$ or $t$ & $p$ & df \\
\hline Males & $50.0 \%$ & $45.5 \%$ & $63.6 \%$ & 0.7 & 0.39 & 1 \\
\hline Age (years) & $17.2(1.6)$ & $18.4(1.0)$ & $17.5(1.3)$ & 1.8 & 0.08 & 20 \\
\hline Wechsler Intelligence Scale IQ & $117(10)^{\mathrm{a}}$ & $105(10)$ & $108(12)$ & 0.3 & 0.81 & 20 \\
\hline \multicolumn{7}{|l|}{ Problem alcohol use criteria } \\
\hline First drink by age 14 & $18.2 \%{ }^{b}$ & $36.4 \%$ & $90.9 \%$ & 7.1 & 0.008 & 1 \\
\hline Ever drunk & $0^{a, b}$ & $63.6 \%$ & $100 \%$ & 4.9 & 0.03 & 1 \\
\hline Alcohol problems & $0.3(0.6)^{a, b}$ & $2.7(2.3)$ & $8(3.0)$ & 4.7 & $<.0001$ & 20 \\
\hline Conduct disorder $\mathrm{dx}$ & 0 & $9.1 \%$ & $27.3 \%$ & 1.2 & 0.27 & 1 \\
\hline Attention deficit disorder $\mathrm{dx}$ & 0 & 0 & $9.1 \%$ & 1.0 & 0.31 & 1 \\
\hline Substance use disorder $\mathrm{dx}^{\mathrm{C}}$ & 0 & 0 & $27.3 \%$ & 3.5 & 0.06 & 1 \\
\hline Any $d x^{d}$ & $0^{\mathrm{b}}$ & $9.1 \%$ & $36.4 \%$ & 2.3 & 0.13 & 1 \\
\hline Marijuana use (ever) & $9.1 \%^{\mathrm{b}}$ & $54.5 \%$ & $81.8 \%$ & 1.9 & 0.17 & 1 \\
\hline \multicolumn{7}{|l|}{ Youth report forme } \\
\hline Withdrawn & $2.2(2.6)$ & $2.0(1.3)$ & $3.3(2.8)$ & 1.4 & 0.18 & 20 \\
\hline Somatic complaints & $2.0(2.9)$ & $1.5(1.2)$ & $2.3(2.1)$ & 1.1 & 0.28 & 20 \\
\hline Anxious/depressed & $4.2(5.0)$ & $2.5(2.3)$ & $5.1(6.6)$ & 1.3 & 0.22 & 20 \\
\hline Social problems & $1.2(1.6)$ & $1.2(1.3)$ & $1.7(1.8)$ & 0.8 & 0.43 & 20 \\
\hline Thought problems & $0.7(1.0)$ & $1.2(1.7)$ & $2.0(3.0)$ & 0.8 & 0.43 & 20 \\
\hline Attention problems & $2.7(2.4)$ & $3.3(2.2)$ & $5.5(3.8)$ & 1.6 & 0.12 & 20 \\
\hline Delinquent behavior & $2.0(1.7)^{b}$ & $3.7(2.5)$ & $6.1(4.6)$ & 1.5 & 0.15 & 20 \\
\hline Aggressive behavior & $5.2(4.5)$ & $6.4(2.5)$ & $11.5(7.7)$ & 2.1 & 0.04 & 20 \\
\hline Total internalizing & $8.0(10.0)$ & $5.6(2.8)$ & $10.1(9.8)$ & 1.5 & 0.16 & 20 \\
\hline Total externalizing & $7.2(5.6)^{b^{\prime}}$ & $10.1(4.7)$ & $17.6(11.4)$ & 2.0 & 0.05 & 20 \\
\hline \multicolumn{7}{|l|}{ Parent Dx (DSM IV Lifetime) } \\
\hline Father alcohol abuse & excl. & $27.3 \%$ & 0 & 3.5 & 0.06 & 1 \\
\hline Father alcohol dependence & excl. & $72.7 \%$ & $100 \%$ & & & \\
\hline Mother alcohol abuse & excl. & $9.1 \%$ & $9.1 \%$ & 0 & na & 1 \\
\hline Mother alcohol dependence & excl. & $18.2 \%$ & $36.4 \%$ & 1.0 & 0.33 & 1 \\
\hline
\end{tabular}

Dx, diagnosis; excl., exclusionary criteria for control group. Standard deviations are given in parentheses.

${ }^{a}$ Control group differs from resilient group at $p<0.05$.

${ }^{\mathrm{b} C o n t r o l}$ group differs from vulnerable group at $p<.05$.

${ }^{\mathrm{C}}$ One subject had alcohol abuse, marijuana abuse and other drug abuse, 1 subject had marijuana abuse and other drug abuse, 1 subject had alcohol abuse and marijuana abuse.

${ }^{\mathrm{d}}$ This includes conduct disorder, attention deficit disorder and/or substance use disorder.

${ }^{e}$ Raw scores.

and $6.3 \pm 0.8$, respectively) although both had greater arousal ratings than the neutral words $(3.9 \pm 0.4 ; p<.0001)$.

There were 3 runs, each including 6 blocks -2 blocks of each condition (positive, negative, neutral) counterbalanced using the Latin Squares design, for a total of 6 block per condition across the entire experiment. Each block had 6 trials (single word presentations) lasting 4 seconds -3 seconds of stimulus-on and 1 second of stimulusoff (during which a fixation mark appeared in the middle of the screen), for a total of 36 words per condition. After each block, participants rested for 18 seconds during which time the screen remained blank. During the rest, participants were instructed to relax and continue watching the screen. The entire protocol in the scanner lasted 12 minutes and 36 seconds. The main contrasts of interest were negative minus neutral blocks and positive minus neutral blocks.

Following scanning, participants completed a questionnaire in which 54 words were listed. For each word, they rated: (1) whether they remembered seeing the word in scanner, (2) the valance of the word, and (3) the arousal of the word. Two-thirds of the words on the list were selected from those viewed in the scanner; one-third was distractors. These were equally divided between positive, negative, and neutral. The instructions given for valence and arousal ratings were identical to those used for ANEW list development (Bradley and Lang, 1999).

MRI Data Acquisition. Whole-brain blood oxygen level dependent (BOLD) fMRI data were acquired on a 3.0 Tesla GE Signa system (Milwaukee, WI) using a standard radio frequency (RF) coil. Functional imaging was performed using a $\mathrm{T} 2{ }^{*}$-weighted pulse sequence with parameters: single-shot combined spiral in/out acquisition (Glover and Law, 2001), gradient echo, repetition time $(\mathrm{TR})=2000$ milliseconds, echo time $(\mathrm{TE})=30$ milliseconds, flip angle $(\mathrm{FA})=90^{\circ}$, field-of-view $(\mathrm{FOV})=20 \mathrm{~cm}, 64 \times 64$ matrix, slice thickness $=3 \mathrm{~mm}$. The entire volume of 30 axial slices was acquired once every 2 seconds and the duration of the scan matched to the duration of the task. The imaging protocol parameters (thin slices, spiral in/out) were selected to minimized signal loss due to magnetic susceptibility effects. In particular, the "spiral in" k-space trajectory eliminates most signal loss due to in-plane dephasing by insuring signals are rephasing for at least 1-point in the image acquisition (Noll, 2002). A high resolution T1 scan was acquired to provide anatomical localization [3-dimensional spoiled gradient recalled echo (3-DSPGR), TR $=25$ milliseconds, $\min \mathrm{TE}, \mathrm{FOV}=24 \mathrm{~cm}$, $256 \times 256$ matrix, slice thickness $=1.4 \mathrm{~mm}$.). Stimuli were presented using the integrated functional imaging system (Psychology Software Tools, Inc., Pittsburg, PA), using an LCD video display in the bore of the MR scanner and a fiberoptic response collection device. Participant motion was minimized with the use of foam pads placed around the head along with a forehead strap. In addition, the importance of keeping as still as possible was emphasized during the Informed Consent process and before scanner entry.

\section{Data Analysis}

Behavioral Data. Recognition memory performance $\left(p^{\prime}\right)$ for each word type was calculated by adjusting the percentage of correct responses to target stimuli $(p)$ by the percentage of incorrect 
responses to distractor stimuli $(f p)$ using the formula: $p^{\prime}=$ $(p-f p) /(1-f p)$ (Epstein et al., 2006). Differences in valence ratings, arousal ratings, recognition memory and reaction times (RTs) between each word type were investigated within each group separately with repeated measures ANOVAS in SPSS. Differences in these measures and in YSR scores between groups were investigated with 1-way ANOVAS with age and IQ as covariates.

fMRI Data. Data were reconstructed off-line using an iterative image reconstruction procedure that allows for simultaneous estimation of the magnetic field distortion and the undistorted images (Sutton et al., 2002, 2003). This procedure has been shown to provide more accurate and complete corrections for magnetic susceptibility distortions. These data were slice time corrected (Oppenheim and Schafer, 1989) and realigned (SPM2; Wellcome Institute of Cognitive Neurology, London, UK). Because of the possibility of excessive subject movement (in excess of $2 \mathrm{~mm}$ ) causing signal artifacts and increased noise, we examined the realignment parameters for each subject. No subjects were eliminated due to excessive motion. For group comparisons, the preprocessed images were co-registered into standard stereotactic space using the intercommissural line as the reference plane, and anatomically normalized by nonlinear warping to a standard stereotactic space as defined by the Montreal Neurological Institute (MNI). A 50-control-point warping algorithm was used for that purpose (Meyer et al., 1997, 1998a,b). The anatomical T1-weighted MR data were first warped, and the transformation matrix was then applied to the realigned functional images. After anatomical normalization, functional images were smoothed with a 6-mm Gaussian filter to reduce residual interindividual anatomical variability.

Statistical analysis was performed with MATLAB (Mathworks, Inc., Natick, MA, USA) and SPM2. For each subject, negative, neutral, positive, and rest blocks were modeled as epochs and planned comparisons (negative minus neutral; positive minus neutral) were computed as linear contrasts. The motion parameters collected during scanning were used in the individual analyses as regressors. Contrast $t$-maps for each subject were anatomically standardized, smoothed (3 mm FWHM), and entered into a second-level, randomeffects ANOVA with group (control, vulnerable, resilient) as the factor. Negative minus neutral and positive minus neutral activations differences between the vulnerable and resilient groups were the main outcomes of interest in the SPM analysis. Areas of activation were deemed significantly different between these 2 groups if they included at least 10 voxels and reached a statistical threshold of $p<0.05$, corrected for multiple comparisons and spatial extent (Friston et al., 1994). In 5 a priori hypothesized regions (amygdala, ventral striatum, insula, prefrontal cortex, orbital frontal cortex), we accepted activation with a spatial extent greater than 10 voxels that reached a statistical threshold of $p<0.001$, uncorrected for multiple comparisons.

The time-series data for the clusters showing a difference in BOLD response between the resilient and vulnerable groups were extracted for all participants using MarsBaR (Brett et al., 2002). From these data, the percent change in BOLD response for negative versus neutral and positive versus neutral was calculated for each region of interest (ROI). These extracted data were used to more fully characterize activation differences due to risk status of the COAs by comparing it with brain responses in these regions in the control subjects. To compare groups (control vs. resilient; control vs. vulnerable), ANCOVAs were performed with sex and IQ as covariates and each ROI as dependent variables.

\section{RESULTS}

\section{Affect and Memory Data}

Valence ratings, arousal ratings, memory scores, and RTs for the total sample and each group are shown in Table 2. All 3 groups rated the 3 word types as significantly different in valence, in the expected direction - i.e., negative words lowest and positive words highest - confirming that the task design worked as intended. The resilient and vulnerable groups showed differences across the 3 word types in arousal ratings whereas the control group did not. However, only the vulnerable group showed the expected pattern, with negative and positive words having higher arousal ratings than neutral

Table 2. Detection Memory, Valence, Arousal and Reaction Time for Negative, Neutral and Positive Words for Total Sample and Control, Resilient and Vulnerable Groups

\begin{tabular}{|c|c|c|c|c|c|c|c|c|c|}
\hline & \multirow[b]{3}{*}{ Group } & \multirow[b]{3}{*}{$n$} & \multicolumn{7}{|c|}{ Word valence } \\
\hline & & & \multicolumn{2}{|c|}{ Negative } & \multicolumn{2}{|c|}{ Neutral } & \multicolumn{2}{|c|}{ Positive } & \multirow{2}{*}{$\frac{\text { ANOVA }}{\text { Within-subject }}$} \\
\hline & & & Mean & SD & Mean & SD & Mean & SD & \\
\hline \multirow[t]{5}{*}{ Valence } & Total & 28 & 2.8 & 1.1 & 5.0 & 0.8 & 6.9 & 1.2 & $F_{2,54}=108.3, p<.0001$ \\
\hline & Controls & 6 & 2.7 & 1.4 & 5.2 & 0.2 & 7.2 & 1.2 & $F_{2,10}=18.8, p<.0001$ \\
\hline & Resilient & 11 & 2.6 & 1.1 & 5.1 & 0.5 & 7.3 & 1.0 & $F_{2,20}=57.9, p<.0001$ \\
\hline & Vulnerable & 11 & 3.1 & 1.0 & 4.9 & 1.2 & 6.4 & 1.3 & $F_{2,20}=40.4, p<.0001$ \\
\hline & ANCOVA & & \multicolumn{2}{|c|}{$F_{4,23}=1.1, p=0.34$} & \multicolumn{2}{|c|}{$F_{4,23}=0.6, p=0.54$} & \multicolumn{2}{|c|}{$F_{4,23}=1.8, p=0.20$} & \\
\hline \multirow[t]{5}{*}{ Arousal } & Total & 28 & 4.0 & 1.6 & 4.1 & 1.3 & 6.1 & 1.6 & $F_{2,54}=24.0, p<.0001$ \\
\hline & Controls & 6 & 3.8 & 2.4 & 3.9 & 1.7 & 6.0 & 2.2 & $F_{2,10}=2.8, p=.11$ \\
\hline & Resilient & 11 & 3.7 & 1.4 & 4.4 & 0.8 & 6.6 & 1.4 & $F_{2,20}=19.7, p<.0001$ \\
\hline & Vulnerable & 11 & 4.3 & 1.4 & 3.9 & 1.5 & 5.6 & 1.3 & $F_{2,20}=8.0, p<.01$ \\
\hline & ANCOVA & & \multicolumn{2}{|c|}{$F_{4,23}=0.4, p=0.70$} & \multicolumn{2}{|c|}{$F_{4,23}=0.1, p=0.88$} & \multicolumn{2}{|c|}{$F_{4,23}=0.9, p=0.42$} & \\
\hline \multirow[t]{5}{*}{ Memory } & Total & 28 & 0.64 & 0.28 & 0.47 & 0.37 & 0.63 & 0.29 & $F_{2,54}=5.9, p<.01$ \\
\hline & Controls & 6 & 0.67 & 0.36 & 0.66 & 0.41 & 0.74 & 0.47 & $F_{2,10}=0.8, p=.41$ \\
\hline & Resilient & 11 & 0.52 & 0.27 & 0.27 & 0.35 & 0.49 & 0.22 & $F_{2,20}=3.4, p<.05$ \\
\hline & Vulnerable & 11 & 0.75 & 0.21 & 0.58 & 0.30 & 0.71 & 0.19 & $F_{2,20}=2.2, p=.13$ \\
\hline & ANCOVA & & \multicolumn{2}{|c|}{$F_{4,23}=2.1, p=0.14$} & \multicolumn{2}{|c|}{$F_{4,23}=2.2, p=0.14$} & \multicolumn{2}{|c|}{$F_{4,23}=1.5, p=0.23$} & \\
\hline \multirow{5}{*}{$\begin{array}{l}\text { Reaction time } \\
\text { (milliseconds) }\end{array}$} & Total & 28 & 959 & 403 & 931 & 386 & 974 & 397 & $F_{2,54}=5.2, p<.01$ \\
\hline & Controls & 6 & 1122 & 436 & 1107 & 448 & 1155 & 456 & $F_{2,10}=1.4, p=.28$ \\
\hline & Resilient & 11 & 855 & 180 & 810 & 173 & 864 & 210 & $F_{2,20}=4.0, p<.05$ \\
\hline & Vulnerable & 11 & 973 & 533 & 955 & 488 & 984 & 494 & $F_{2,20}=0.7, p=.48$ \\
\hline & ANCOVA & & $F_{4,23}=$ & 0.63 & $F_{4,23}=$ & 0.69 & $F_{4,23}=$ & 0.82 & $F_{4,23}=0.5, p=.63$ \\
\hline
\end{tabular}


words. Combined, the total sample showed the expected pattern of memory scores, with higher detection memory for negative and positive words than neutral words, although this was significant only in the resilient group. The total sample showed the expected pattern of RTs, with slower RTs to affective words than neutral words. Each group showed this pattern, although it was only significant in the resilient group. Results of the between-group ANCOVAs indicated no differences in RTs, valence and arousal ratings or detection memory for any of the word types.

\section{Behavioral Adjustment}

Group averages from the YSR are reported in Table 1. The between-group ANCOVAs revealed group differences in the externalizing broad-band scale $(F=3.9$; df $=4,23$; $p<0.05$ ). The vulnerable group had more externalizing behavior than both the resilient and the low risk control groups, consistent with an antisocial pathway (Zucker, 2006), and with our earlier findings of externalizing differences between vulnerable and resilient groups in very early childhood and in early adolescence, as well as no differences between resilient and vulnerable groups in internalizing behavior in early adolescence (Zucker et al., 2003). We therefore examined the individual scales comprising the externalizing scale, identifying group differences on the aggression subscale $(\mathrm{F}=3.6 ; \mathrm{df}=4,23 ; p<0.05)$ due to more aggression in the vulnerable group than the resilient group. Group differences on the delinquent subscale approached significance $(F=3.0 ;$ df $=4,23 ; p=0.07)$ due to more delinquent behavior in the vulnerable group than the control group.

\section{Neuroimaging Results}

Negative-Neutral Contrast. The vulnerable group had greater activation than the resilient group in the right dorsal medial prefrontal cortex (DMPFC; BA9/10; Table 3 and Fig. $1 A$ ). The extracted data revealed that this difference was due to decreased BOLD response with negative words compared with neutral words in the resilient group and increased BOLD response (i.e., more response to negative than neutral) in the vulnerable group (Fig. 1C).

Vulnerable subjects also had less activation compared with resilient subjects in the OFG bilaterally (BA11), the left insula/putamen, the extended amygdala, bilaterally and the ventral striatum including the nucleus accumbens bilaterally (Table 3 and Fig. 1b). These differences in BOLD activation were due to increased BOLD response with negative words versus neutral words in the resilient group and decreased BOLD response in the vulnerable group (Fig. 1C).

Positive-Neutral Contrast. Vulnerable subjects had greater activation than resilient subjects in the DMPFC extending from a peak in the superior frontal gyrus (BA8/9) to the medial frontal gyrus $(9 / 10$; Table 3 and Fig. $2 A)$. This area encompassed the same region showing increased activation in this group for the negative versus neutral words contrast, above. The vulnerable group had an additional peak of increased activation in the medial prefrontal cortex ventrally (BA9/10) as well. These differences were due to decreased BOLD response with positive words versus neutral words in the resilient group and increased BOLD response in the vulnerable group (Fig. 2C).

No decreases in activation in the vulnerable group versus the resilient group were observed at the standard statistical threshold. However, at a more lenient threshold $(p<0.005)$ lower activation in the vulnerable group was observed in the left ventral striatum and right OFG (Table 3 and Fig. 2B). Both these areas coincided with those found to have lower activity for the negative versus neutral contrast in the vulnerable group. This difference in BOLD activation was again due to the groups having opposite patterns of response: increased

Table 3. SPM Results for Comparison Between Resilient and Vulnerable Groups

\begin{tabular}{|c|c|c|c|c|c|c|c|c|}
\hline & \multicolumn{4}{|c|}{ Negative-neutral words } & \multicolumn{4}{|c|}{ Positive-neutral words } \\
\hline & $\begin{array}{c}\text { MNI space } \\
x, y, z\end{array}$ & $\begin{array}{c}\text { Cluster } \\
\text { size }\left(\mathrm{mm}^{3}\right)\end{array}$ & Peak $t$ & $\begin{array}{l}\text { Voxel } \\
\text { level } p \\
\text { (uncorr.) }\end{array}$ & $\begin{array}{c}\text { MNI space } \\
\quad x, y, z\end{array}$ & $\begin{array}{c}\text { Cluster } \\
\text { size }\left(\mathrm{mm}^{3}\right)\end{array}$ & Peak $t$ & $\begin{array}{l}\text { Voxel level } \\
p \text { (uncorr.) }\end{array}$ \\
\hline Brain region & \multicolumn{8}{|c|}{ Resilient > Vulnerable } \\
\hline R OFG (BA11) & $24,45,-12$ & 1547 & 4.17 & $<0.0001$ & $23,46,-9$ & 131 & 2.88 & 0.002 (n.s.) \\
\hline L OFG (BA11) & $-22,40,-16$ & 1942 & 4.16 & $<0.0001$ & & & & \\
\hline $\mathrm{L}$ insula/putamen & $-29,10,-11$ & 2048 & 3.98 & $<0.0001$ & & & & \\
\hline L extended amygdala & $-24,-4,-6$ & & 3.91 & $<0.0001$ & & & & \\
\hline L VS/NAcC & $-19,9,-9$ & & 3.85 & $<0.0001$ & $-18,11,-10$ & 805 & 2.97 & 0.002 (n.s) \\
\hline $\mathrm{R} V \mathrm{~S} / \mathrm{NACC}$ & $18,10,-10$ & 904 & 3.51 & $<0.0001$ & & & & \\
\hline \multirow[t]{2}{*}{$\mathrm{R}$ extended amygdala } & $24,-7,-11$ & & 3.19 & 0.001 & & & & \\
\hline & \multicolumn{8}{|c|}{ Vulnerable > Resilient } \\
\hline DM PFC (BA8/9/10) & $2,52,42$ & 633 & 3.56 & $<0.0001$ & $10,41,46$ & 1788 & 4.24 & $<.0001$ \\
\hline & & & & & $0,51,41$ & & 4.15 & $<.0001$ \\
\hline Medial PFC (BA9/10) & & & & & $4,52,15$ & 296 & 3.33 & $<.0001$ \\
\hline
\end{tabular}

L, left hemisphere; R, right hemisphere; OFG, orbital frontal gyrus; BA, Brodmann's Area; NAcc, nucleus accumbens; VS, ventral striatum; DM, dorsomedial; PFC, prefrontal cortex. 
A. Vulnerable > Resilient
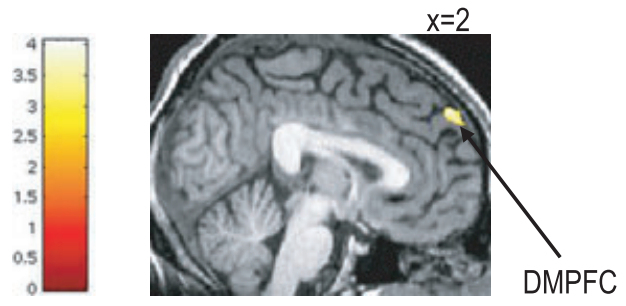

C. Control vs. Resilient and Vulnerable Groups

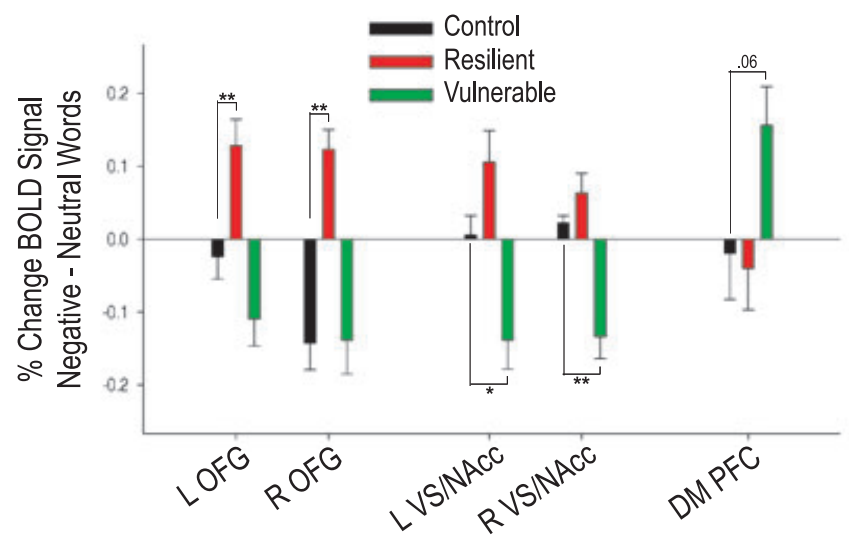

B. Resilient > Vulnerable

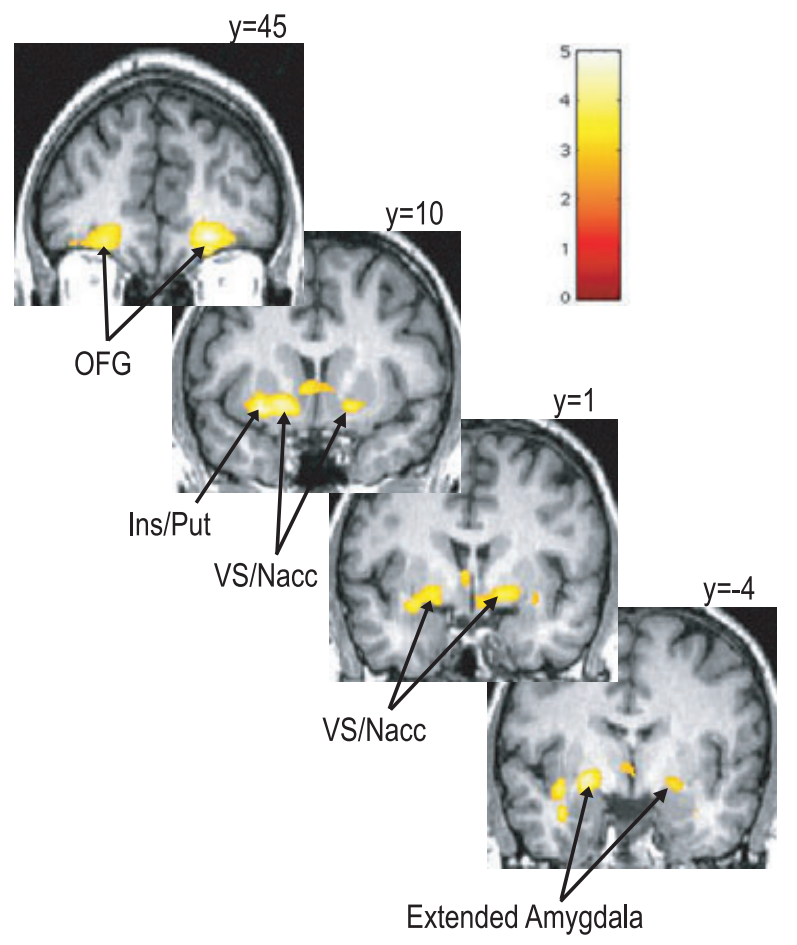

Fig. 1. Activation differences between groups for the negative minus neutral contrast. (A) Statistical parametric map showing regions where activation was greater in the vulnerable group than the resilient group. (B) Statistical parametric map showing regions where activation was greater in the resilient group than the vulnerable group. (C) Graph of extracted data showing percent signal change in control, resilient, and vulnerable groups. All differences between resilient and vulnerable groups are significant at $p<0.001$. *Different from control group at $p<0.05$; ${ }^{* *}$ different from control group at $p<0.01$. L, left hemisphere; R, right hemisphere; OFG, orbital frontal gyrus; BA, Brodmann's Area; NAcc, nucleus accumbens; VS, ventral striatum; DM, dorsomedial; PFC, prefrontal cortex. Color bars represent $t$-values. Note: All differences between resilient and vulnerable groups are significant at $p<0.001$.

\section{A. Vulnerable > Resilient}

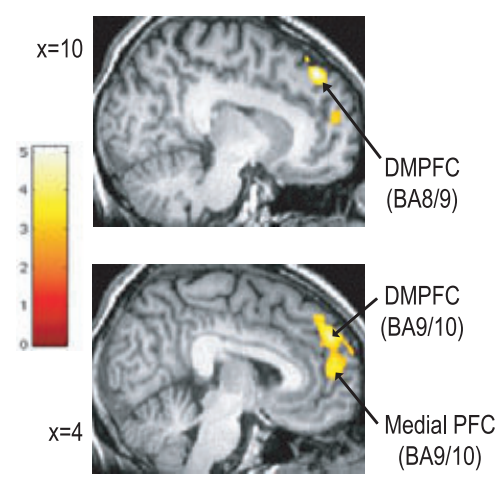

\section{B. Resilient > Vulnerable}

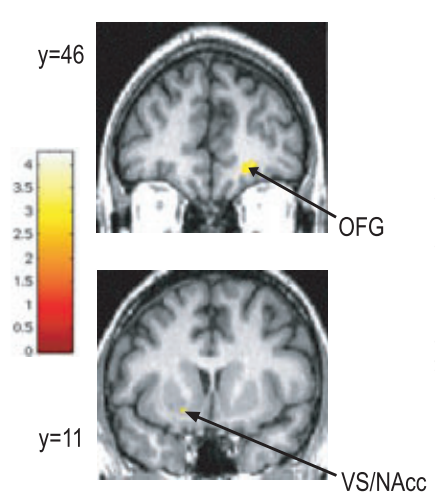

C. Control vs. Resilient and Vulnerable Groups

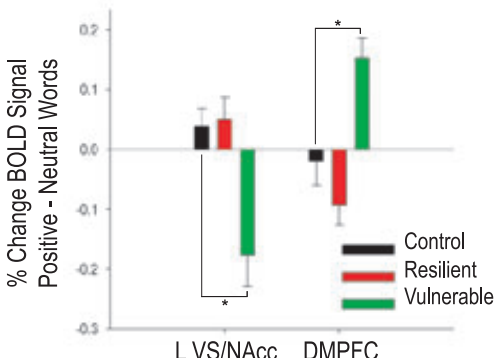

Fig. 2. Activation differences between groups for the positive minus neutral contrast. (A) Statistical parametric map showing regions where activation was greater in the vulnerable group than the resilient group. (B) Statistical parametric map showing regions where activation was greater in the resilient group than the vulnerable group. (C) Graph of extracted data showing percent signal change in control, resilient, and vulnerable groups. All differences between resilient and vulnerable groups are significant at $p<0.01$. ${ }^{*}$ Different from control group at $p<0.05$; ${ }^{* \star}$ different from control group at $p<0.01$. L, left hemisphere; R, right hemisphere; OFG, orbital frontal gyrus; BA, Brodmann's Area; NAcc, nucleus accumbens; VS, ventral striatum; DM, dorsomedial; PFC, prefrontal cortex. Color bars represent t values. Note: All differences between resilient and vulnerable groups are significant at $p<0.01$.

BOLD response with positive words versus neutral words in the resilient group, but decreased BOLD response in the vulnerable group (Fig. 2C).
Comparisons With Control Group. For each ROI showing a difference between resilient and vulnerable groups (Table 3), percent changes were calculated for the control 
group and $t$-tests performed to determine differences between each risk/COA group and controls (Table 4). The resilient group showed significantly greater activation in the right and left OFG in the negative minus neutral contrast (Fig. 1C) and a trend for greater activation in the right OFG to positive versus neutral words compared with controls whereas the vulnerable group did not differ from controls in their activation of the OFG. In contrast, the vulnerable group showed significantly lower activation for negative minus neutral contrasts in the ventral striatum, bilaterally (Fig. 1C), and the right extended amygdala, as well as for positive minus neutral contrasts in the left ventral striatum (Fig. 2C) than controls. The resilient group did not differ from controls in these regions. In addition, the vulnerable group had greater activation of the DMPFC in the positive minus neutral contrast than the controls (Fig. 2C). In the negative minus neutral contrast this effect approached significance (Fig. $1 ; p=0.06$ ). DMPFC activation did not differ between the resilient and control groups.

Correlations With YSR. Nonorthogonal correlations were performed between percent changes in each ROI from Table 3 and YSR externalizing and aggression scores. For negative versus neutral words, YSR externalizing correlated negatively with percent change in the left extended amygdala and the right ventral striatum and positively with percent change in the DMPFC (Fig. 3). These regions also correlated with YSR aggression (left extended amygdala: $r=-0.58, p<0.01$; right ventral striatum: $r=-0.56, p<0.01$; DMPFC: $r=0.46, p<0.01$ ).

From the positive versus neutral contrast, externalizing correlated negatively with percent change in the left ventral striatum and positively with percent change in the DMPFC (Fig. 3). DMPFC activation also correlated with YSR aggression $(r=.39, p<0.05)$ and a correlation between the left ventral striatum and YSR aggression approached significance $(r=-0.36, p=0.06)$.

\section{DISCUSSION}

The 2 primary aims of this study were to identify neural activation mechanisms that may mark protection or vulnerability to AUD in children of alcoholic fathers, and to map the same activation patterns in relation to risk behavior (here, externalizing behavior). The guiding conceptual framework was that the functioning of affective and behavioral regulation networks in the brain may serve as such mechanisms. Consistent with that framework, the resilient and vulnerable groups were distinguished from one another by remarkably consistent inverse patterns of activation in response to the processing of lexical emotional stimuli. These patterns were most apparent with regard to management of negative affective stimuli, with the vulnerable group - the group with the most externalizing behavior - displaying a pattern of greater control-i.e., more DMPFC activation, and lesser subcortical activation. Consistent with that group effect, across all groups, more externalizing behavior and aggression was associated with more activation in DMPFC and less activation subcortically.

These results suggest separate pathways of risk and resilience in the COAs. First, the COA group that was not prone to early problem drinking (the resilient group) had more activation of OFG than controls in response particularly to negative affect stimuli, but also to some extent in response to positive affect stimuli. The OFG is involved in the monitoring and evaluation of the affective value of stimuli, allowing for appropriate behavioral responses (Kringelbach and Rolls, 2004; Rolls, 2004). The resilient group also had increased left insula activation to negative words. The insula is involved in evaluating internally

Table 4. BOLD Activations in Vulnerable and Resilient Groups Compared to Control Group

\begin{tabular}{|c|c|c|c|c|c|c|c|c|c|c|}
\hline \multirow[b]{3}{*}{ Brain region } & \multicolumn{5}{|c|}{ Resilient versus control } & \multicolumn{5}{|c|}{ Vulnerable versus control } \\
\hline & \multirow[b]{2}{*}{ Direction } & \multicolumn{2}{|c|}{ Negative } & \multicolumn{2}{|c|}{ Positive } & \multirow[b]{2}{*}{ Direction } & \multicolumn{2}{|c|}{ Negative } & \multicolumn{2}{|c|}{ Positive } \\
\hline & & $F$ & $p$ & $F$ & $p$ & & $F$ & $p$ & $F$ & $p$ \\
\hline L OFG (BA11) & + & 14.1 & 0.002 & & & $=$ & & & & \\
\hline R OFG (BA11) & + & 16.8 & 0.001 & 2.1 & 0.17 & $=$ & & & & \\
\hline $\mathrm{L}$ insula/putamen & + & 6.1 & 0.03 & & & $=$ & & & & \\
\hline L extended amygdala & $=$ & & & & & $=$ & & & & \\
\hline $\mathrm{R}$ extended amygdala & $=$ & & & & & - & 4.9 & 0.04 & & \\
\hline L VS/NAcc & $=$ & & & & & - & 5.8 & 0.03 & 7.4 & 0.02 \\
\hline $\mathrm{R}$ VS/NAcc & $=$ & & & & & - & 11.5 & 0.005 & & \\
\hline DM PFC (BA8/9/10) & $=$ & & & & & + & 4.1 & 0.06 & 8.6 & 0.01 \\
\hline Medial PFC (BA10/32) & $=$ & & & & & $=$ & & & & \\
\hline
\end{tabular}

L, left hemisphere; R, right hemisphere; OFG, orbital frontal gyrus; BA, Brodmann's Area; NAcc, nucleus accumbens; VS, ventral striatum; DM, dorsomedial; PFC, prefrontal cortex.

+ indicates an increase in percent signal change relative to the control group; - indicates a decrease in percent signal change relative to the control group; = indicates no significant difference from control group; Negative refers to the negative minus neutral contrast; positive refers to the positive minus neutral contrast. 


\section{A. Negative vs. Neutral}
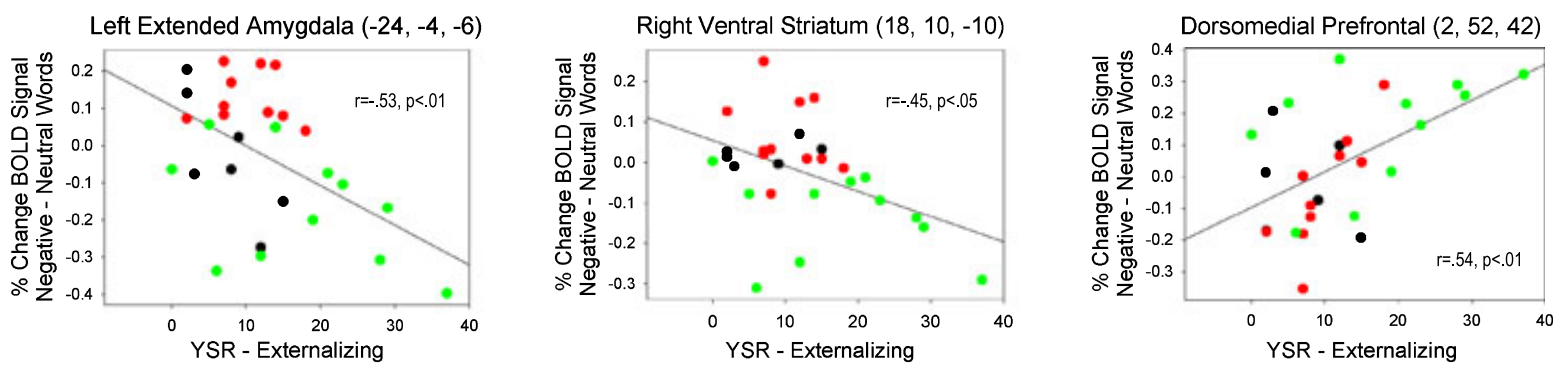

\section{B. Positive vs. Neutral}
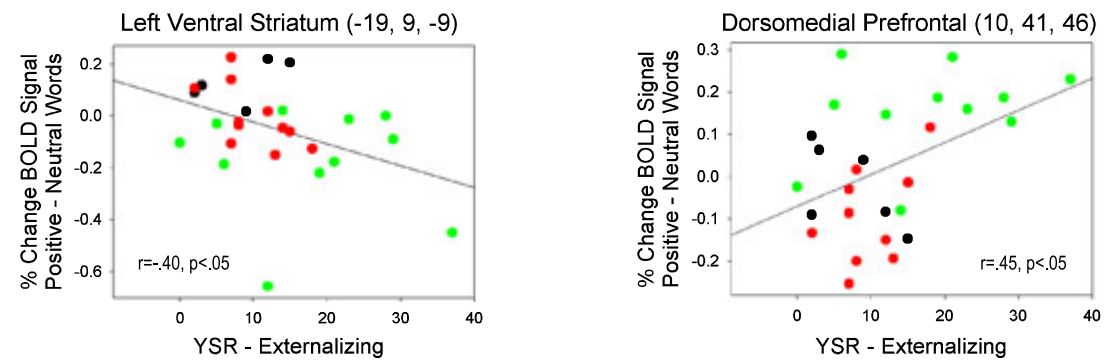

Fig. 3. Correlations between YSR externalizing and ROI activations for total sample. (A) Correlations between YSR externalizing and percent signal change for negative minus neutral in left extended amygdala (left), right ventral striatum (middle) and dorsomedial prefrontal cortex (right). (B) Correlations between YSR externalizing and percent signal change for positive minus neutral in left ventral striatum (left) and dorsomedial prefrontal cortex. Black circles indicate the control group; red circles indicate the resilient group; green circles indicate the vulnerable group.

generated emotions and the monitoring of ongoing internal emotional state (Phan et al., 2002).

The present findings, then, are consistent with the hypothesis that resilient youth have enhanced monitoring of emotionally arousing stimuli, even compared with typically developing youth. Yet, in an important nuance, they did not suppress the emotional experience, as indicated by an activation of the subcortical emotional regions that paralleled that of the control group. Therefore, we suggest that they were prepared to modify behavioral response while maintaining affective response to these stimuli. This pattern of response in resilient youth may represent increased flexibility in emotional and social behavior. Barkley (1997) elaborated a theory suggesting that externalizing risk is rooted in failure to adequately delay response. These youth may be exhibiting precisely that ability to delay external response to arousing stimuli, while internally processing those stimuli. In short, this may be a "reflective" pattern of approach to the world, captured in neural activation pattern. It is not difficult to speculate how this pattern might protect these at risk youth from substance misuse: they are able to respond to the emotional stimuli, but demonstrate enhanced monitoring that may allow for the inhibition of inappropriate responding, buying time for flexible response options based on well-processed information.

Secondly, and in contrast, the vulnerable group displayed no differences from the control group in emotional monitoring and behavioral regulation systems (OFG and insula), suggesting that weakness in that system is not a risk factor.
Rather, they had a different pattern of risk that was not simply the inverse of the protective pattern seen in the resilient group. They demonstrated over-activation of DMPFC and an atypical under-activation of key emotion processing regions (particularly extended amygdala and ventral striatum). Although this pattern was more notable in regard to negative affect, it was also observed to a lesser extent with positive affect. Furthermore, this group showed higher externalizing behaviors, which correlated positively with DMPFC activation and negatively with extended amygdala and ventral striatal activation. All of this may be consistent with a reactive approach to the world, in which affect is not fully processed. Supporting this interpretation, neuroimaging studies have consistently shown the involvement of the DMPFC with conscious self-monitoring of emotional responses (Beauregard et al., 2001; Kuchinke et al., 2006; Levesque et al., 2003, 2004; Phan et al., 2005). For example, during the voluntary suppression of negative affect in healthy adults, activation in the dorsal medial and lateral prefrontal cortex increased and that in the nucleus accumbens and extended amygdala decreased (Phan et al., 2005). It has been suggested that emotional information is conveyed from limbic regions to the prefrontal cortex allowing conscious, voluntary emotional self-regulation (Levesque et al., 2003, 2004). Therefore, one interpretation of the present findings is that the vulnerable youth were recruiting an emotional control system that was suppressing emotional response.

One can question whether, because these youth have begun to drink, this pattern represents a failure of 
emotional engagement that may influence the temptation to drink, or failure of maturation of emotional systems, perhaps secondary to early drinking, or both. Although the present data do not allow definitive differentiation between these possibilities, their pattern weighs against a neurotoxic effect of alcohol use driving the results. If the functional brain abnormalities observed in the vulnerable group were attributable to the neurotoxic effects of alcohol, one might expect a general deficiency in the brain responses in this group. Instead, the responses in the ventral striatum and prefrontal cortex were very similar between control and resilient groups and the vulnerable group, instead of showing less reactivity in these regions, displays the opposite pattern of responding than the other groups. This very specificity of response patterns, rather than a diffuse inefficiency of response in 1 group, weighs in favor of a basic difference in the pattern of adaptive organization in the brains of the vulnerable youth, as opposed to a generalized deficit in responding.

Furthermore, although adolescents with heavy alcohol use retain less verbal and nonverbal information (Brown and Tapert, 2004); in the present study, the vulnerable group did not show a deficit in memory and, in fact showed a trend for better recognition memory for all word types than the resilient group. This is probably because, even though they have begun to drink, the late-adolescent in our study have not yet engaged in years of heavy drinking. In all, then, it can be tentatively proposed that the fMRI effects observed here reflect preexisting vulnerability, rather than mainly effects of alcohol use.

Alterations in the functioning of the ventral striatum and prefrontal cortex have been proposed previously to underlie vulnerability to alcoholism (Piazza et al., 1991; Volkow et al., 2002). Specifically, receptor PET studies have found significant reductions in striatal dopamine D2 receptors (Heinz et al., 2004; Hietala et al., 1994; Martinez et al., 2005; Volkow et al., 1996, 2002) and blunted dopamine release (Martinez et al., 2005) in adult alcoholics. Volkow et al. (2002) have suggested that this may represent a predisposing factor in alcoholism. Furthermore, because D2 receptor availability is positively associated with OFG activity, individuals with decreased D2 receptor availability also have decreased OFG functioning (Goldstein and Volkow, 2002). However, those findings were based on subjects who had moved beyond risk into diagnosis. Therefore, effects due to alcohol could not be entirely disentangled from effects prior to serious alcohol use. In a recent study, however, nonalcoholic adult members of alcoholic families had higher dopamine D2 receptor availability in the caudate and ventral striatum than nonalcoholic controls, which was associated with increased resting glucose metabolism in the $\mathrm{OFG}$ and prefrontal cortex (BA8/9) - paralleling the regions observed in the present study (Volkow et al., 2006). Taken together, these studies in alcoholics and nonalcoholic members of alcoholic families suggest that low levels of striatal D2 recep- tors and prefrontal functioning confer vulnerability, whereas high levels of striatal D2 receptors and prefrontal functioning are protective (Volkow et al., 2004, 2006). The present study provides support for that hypothesis but adds nuance to it by pointing to dissociable circuits within these regions conferring protection and vulnerability.

Because of the small sample size in each group, these results should be considered preliminary. Although the differences did not reach significance, the vulnerable group had more individuals who had used marijuana and a higher rate of externalizing disorder diagnoses than the resilient group. These characteristics are consistent with the expectation driving this research that vulnerable individuals are more likely to move into AUD diagnosis and, in fact, some of them have. However, it also prevents the strict interpretation of the results as relating to AUD risk specifically as opposed to externalizing disorders more generally. Another potentially confounding factor is the greater parental loading of alcoholism in the vulnerable group despite our matching on family alcoholism riski.e., severity of father's alcoholism (abuse vs. dependence) and the presence of an alcoholic mother. Further studies with larger samples are necessary to tease apart possible contributions of these factors.

In conclusion, within the limitations noted, the findings suggest separable pathways through which resiliency and vulnerability are conferred in COAs. This is an important step toward understanding the neural circuitry which underlies the heterogeneity of risk in this population. A more nuanced understanding of how the functioning of different types of control mechanisms may influence outcome has the potential to lead to more efficacious prevention and intervention strategies. In addition, follow-up assessments will be done to determine whether individuals in the vulnerable group move into diagnosis and whether the resilient group was indeed resilient.

\section{ACKNOWLEDGMENTS}

This work was supported by K01 DA020088 to MMH, R01 AA12217 and R37 AA07065 to RAZ, and a NARSAD Independent Investigator award to JKZ.

\section{REFERENCES}

Achenbach TM (1991) Manual for the Youth Self-Report Form and 1991 Profile. University Associates in Psychiatry, Burlington, VT.

Aron AR, Fletcher PC, Bullmore ET, Sahakian BJ, Robbins TW (2003a) Stop-signal inhibition disrupted by damage to right inferior frontal gyrus in humans. Nat Neurosci 6:115-116.

Aron AR, Poldrack RA (2005) The cognitive neuroscience of response inhibition: relevance for genetic research in attention-deficit/hyperactivity disorder. Biol Psychiatry 57:1285-1292.

Aron AR, Schlaghecken F, Fletcher PC, Bullmore ET, Eimer M, Barker R, Sahakian BJ, Robbins TW (2003b) Inhibition of subliminally primed responses is mediated by the caudate and thalamus: evidence from functional MRI and Huntington's disease. Brain 126 (Pt 3):713-723. 
Barkley RA (1997) Behavioral inhibition, sustained attention, and executive functions: constructing a unifying theory of ADHD. Psychol Bull 121:6594.

Beauregard M, Levesque J, Bourgouin P (2001) Neural correlates of conscious self-regulation of emotion. J Neurosci 21:RC165.

Blair RJ, Peschardt KS, Budhani S, Mitchell DG, Pine DS (2006) The development of psychopathy. J Child Psychol Psychiatry 47:262-276.

Bradley MM, Lang PJ (1999) Affective Norms for English Words (ANEW). NIMH Center for the Study of Emotion and Attention, University of Florida, Gainsvill.

Brett M, Anton J-L, Valabregue R, Poline JB (2002) Region of interest analysis using an SPM toolbox, Paper Presented at the 8th International Conference on Functional Mapping of the Human Brain, Sendai, Japan.

Brown SA, Tapert SF (2004) Adolescence and the trajectory of alcohol use: basic to clinical studies. Ann N Y Acad Sci 1021:234-244.

Casey BJ, Castellanos FX, Giedd JN, Marsh WL, Hamburger SD, Schubert AB, Vauss YC, Vaituzis AC, Dickstein DP, Sarfatti SE, Rapoport JL (1997) Implication of right frontostriatal circuitry in response inhibition and attention-deficit/hyperactivity disorder. J Am Acad Child Adolesc Psychiatry $36: 374-383$.

Casey BJ, Thomas KM, Davidson MC, Kunz K, Franzen PL (2002) Dissociating striatal and hippocampal function developmentally with a stimulusresponse compatibility task. J Neurosci 22:8647-8652.

Caspi A, Moffitt TE, Newman DL, Silva PA (1996) Behavioral observations at age 3 years predict adult psychiatric disorders. Longitudinal evidence from a birth cohort. Arch Gen Psychiatry 53:1033-1039.

Chassin L, Pillow DR, Curran PJ, Molina BS, Barrera M Jr (1993) Relation of parental alcoholism to early adolescent substance use: a test of three mediating mechanisms. J Abnorm Psychol 102:3-19.

Chassin L, Ritter J (2001) Vulerability to substance use disorders in childhood and adolescence, in Vulnerability to Psychopathology: Risk Across the Lifespan (Ingram R, Price J eds), pp 107-134. The Guilford Press, New York.

Clark DB, Cornelius JR, Kirisci L, Tarter RE (2005) Childhood risk categories for adolescent substance involvement: a general liability typology. Drug Alcohol Depend 77:13-21.

Clark DB, Parker AM, Lynch KG (1999) Psychopathology and substancerelated problems during early adolescence: a survival analysis. J Clin Child Psychol 28:333-341.

Cloninger CR, Sigvardsson S, Bohman M (1988) Childhood personality predicts alcohol abuse in young adults. Alcohol Clin Exp Res 12:494-505.

Colder CR, Chassin L (1993) The stress and negative affect model of adolescent alcohol use and the moderating effects of behavioral undercontrol. J Stud Alcohol 54:326-333.

Costello A, Edelbrook C, Dulcan M, Kalas R, Klanc S (1984) Development and Testing of the NIMH Diagnostic Interview Schedule for Children in a Clinic Population. Center for Epidemiological Studies, NIMH, Rockville, MD

De Bellis MD, Clark DB, Beers SR, Soloff PH, Boring AM, Hall J, Kersh A, Keshavan MS (2000) Hippocampal volume in adolescent-onset alcohol use disorders. Am J Psychiatry 157:737-744.

Epstein J, Pan H, Kocsis JH, Yang Y, Butler T, Chusid J, Hochberg H, Murrough J, Strohmayer E, Stern E, Silbersweig DA (2006) Lack of ventral striatal response to positive stimuli in depressed versus normal subjects. Am J Psychiatry 163:1784-1790.

Friston KJ, Worsley KJ, Frackowiak RSJ, Mazziotta JC, Evans AC (1994) Assessing the significance of focal activations using their spatial extent. Human Brain Mapping 1:210-220.

Glahn DC, Lovallo WR, Fox PT (2007) Reduced amygdala activation in young adults at high risk of alcoholism: studies from the Oklahoma Family Health Patterns Project. Biol Psychiatry 61:1306-1309.

Glover GH, Law CS (2001) Spiral-in/out BOLD fMRI for increased SNR and reduced susceptibility artifacts. Magn Reson Med 46:515-522.

Goldstein RZ, Volkow ND (2002) Drug addiction and its underlying neurobiological basis: neuroimaging evidence for the involvement of the frontal cortex. Am J Psychiatry 159:1642-1652.
Grant BF, Dawson DA (1997) Age at onset of alcohol use and its association with DSM-IV alcohol abuse and dependence: results from the National Longitudinal Alcohol Epidemiologic Survey. J Subst Abuse 9:103-110.

Hariri AR, Bookheimer SY, Mazziotta JC (2000) Modulating emotional responses: effects of a neocortical network on the limbic system. Neuroreport 11:43-48.

Hariri AR, Tessitore A, Mattay VS, Fera F, Weinberger DR (2002) The amygdala response to emotional stimuli: a comparison of faces and scenes. Neuroimage 17:317-323.

Heath A (1995) Genetic influences on alcoholism risk? A review of adoption and twin studies Alcohol Health Res World 19:166-171.

Heath AC, Bucholz KK, Madden PA, Dinwiddie SH, Slutske WS, Bierut LJ, Statham DJ, Dunne MP, Whitfield JB, Martin NG (1997) Genetic and environmental contributions to alcohol dependence risk in a national twin sample: consistency of findings in women and men. Psychol Med 27:13811396.

Heinz A, Siessmeier T, Wrase J, Hermann D, Klein S, Grusser-Sinopoli SM, Flor H, Braus DF, Buchholz HG, Grunder G, Schreckenberger M, Smolka MN, Rosch F, Mann K, Bartenstein P (2004) Correlation between dopamine $\mathrm{D}(2)$ receptors in the ventral striatum and central processing of alcohol cues and craving. Am J Psychiatry 161:1783-1789.

Hietala J, West C, Syvalahti E, Nagren K, Lehikoinen P, Sonninen P, Ruotsalainen U (1994) Striatal D2 dopamine receptor binding characteristics in vivo in patients with alcohol dependence. Psychopharmacology (Berl) 116:285-290.

Hill SY, De Bellis MD, Keshavan MS, Lowers L, Shen S, Hall J, Pitts T (2001) Right amygdala volume in adolescent and young adult offspring from families at high risk for developing alcoholism. Biol Psychiatry 49:894-905.

Hyman SE, Malenka RC (2001) Addiction and the brain: the neurobiology of compulsion and its persistence. Nat Rev Neurosci 2:695-703.

Jacob T, Sher KJ, Bucholz KK, True WT, Sirevaag EJ, Rohrbaugh J, Nelson E, Neuman RJ, Todd RD, Slutske WS, Whitfield JB, Kirk KM, Martin NG, Madden PAF, Heath AC (2001) An integrative approach for studying the etiology of alcoholism and other addictions. Twin Res 4:103-118.

Kalivas PW, Stewart J (1991) Dopamine transmission in the initiation and expression of drug- and stress-induced sensitization of motor activity. Brain Res Brain Res Rev 16:223-244.

Kendler KS, Neale MC, Heath AC, Kessler RC, Eaves LJ (1994) A twin-family study of alcoholism in women. Am J Psychiatry 151:707-715.

Kensinger EA, Schacter DL (2006) Processing emotional pictures and words: effects of valence and arousal. Cogn Affect Behav Neurosci 6:110-126.

Koob GF (1999) The role of the striatopallidal and extended amygdala systems in drug addiction. Ann N Y Acad Sci 877:445-460.

Koob GF (2003) Alcoholism: allostasis and beyond. Alcohol Clin Exp Res 27:232-243.

Kringelbach ML, Rolls ET (2004) The functional neuroanatomy of the human orbitofrontal cortex: evidence from neuroimaging and neuropsychology. Prog Neurobiol 72:341-372.

Kuchinke L, Jacobs AM, Grubich C, Vo ML, Conrad M, Herrmann M (2005) Incidental effects of emotional valence in single word processing: an fMRI study. Neuroimage 28:1022-1032.

Kuchinke L, Jacobs AM, Vo ML, Conrad M, Grubich C, Herrmann M (2006) Modulation of prefrontal cortex activation by emotional words in recognition memory. Neuroreport 17:1037-1041.

Levesque J, Eugene F, Joanette Y, Paquette V, Mensour B, Beaudoin G, Leroux JM, Bourgouin P, Beauregard M (2003) Neural circuitry underlying voluntary suppression of sadness. Biol Psychiatry 53:502-510.

Levesque J, Joanette Y, Mensour B, Beaudoin G, Leroux JM, Bourgouin P, Beauregard M (2004) Neural basis of emotional self-regulation in childhood. Neuroscience 129:361-369.

Maddock RJ, Garrett AS, Buonocore MH (2003) Posterior cingulate cortex activation by emotional words: fMRI evidence from a valence decision task. Hum Brain Mapp 18:30-41.

Martinez D, Gil R, Slifstein M, Hwang DR, Huang Y, Perez A, Kegeles L, Talbot P, Evans S, Krystal J, Laruelle M, Abi-Dargham A (2005) Alcohol 
Dependence Is Associated with Blunted Dopamine Transmission in the Ventral Striatum. Biol Psychiatry 58:779-786.

Mason WA, Windle M (2002) Reciprocal relations between adolescent substance use and delinquency: a longitudinal latent variable analysis. J Abnorm Psychol 111:63-76.

Mayzer R, Wong M, Puttler L, Fitzgerald H, Zucker R (2001) Onset of Alcohol Use: Profiling adolescents characterized as "Early Drinkers", Paper Presented at the Annual Meeting of the American Society of Criminology, Atlanta, GA.

McGue M, Iacono WG, Legrand LN, Malone S, Elkins I (2001) Origins and consequences of age at first drink. I. Associations with substance-use disorders, disinhibitory behavior and psychopathology, and P3 amplitude. Alcohol Clin Exp Res 25:1156-1165.

Medina KL, Schweinsburg AD, Cohen-Zion M, Nagel BJ, Tapert SF (2007) Effects of alcohol and combined marijuana and alcohol use during adolescence on hippocampal volume and asymmetry. Neurotoxicol Teratol 29:141-152.

Meyer CR, Boes JL, Kim B, Bland PH (1998b) Evaluation of control point selection in automatic mutual information driven, 3D warping, in Lecture Notes in Computer Science (Wells WM, Colchester A, Delp S eds), vol 4196, pp 944-951. Springer, Boston, MA.

Meyer CR, Boes JL, Kim B, Bland PH, Frey KA (1998a) Warping normal patients into the ICBM atlas by maximizing MI, Paper Presented at the Functional Mapping of the Human Brain, Montreal, Quebec.

Meyer CR, Boes JL, Kim B, Bland PH, Zasadny KR, Kison PV, Koral K, Frey KA, Wahl RL (1997) Demonstration of accuracy and clinical versatility of mutual information for automatic multimodality image fusion using affine and thin-plate spline warped geometric deformations. Med Image Anal 1:195-206.

Nagel BJ, Schweinsburg AD, Phan V, Tapert SF (2005) Reduced hippocampal volume among adolescents with alcohol use disorders without psychiatric comorbidity. Psychiatry Res 139:181-190.

Naqvi NH, Rudrauf D, Damasio H, Bechara A (2007) Damage to the insula disrupts addiction to cigarette smoking. Science 315:531-534.

National Institute on Alcohol Abuse and Alcoholism (2000) Alcohol involvement over the life course, In NIAAA, Tenth Special Report to the U.S. Congress on Alcohol and Health: Highlights From Current Research, pp 28-53. U.S. Department of Health and Human Services, Bethesda, MD.

Nestler E (1999) Cellular and Molecular Mechanisms of Addiction, in Neurobiology of Mental Illness (Charney D, Nestler EJ, Bunney BS, eds), pp 578-590. Oxford University Press, New York.

Nigg JT, Casey BJ (2005) An integrative theory of attention-deficit/ hyperactivity disorder based on the cognitive and affective neurosciences. Dev Psychopathol 17:785-806.

Nigg JT, Nikolas M, Friderici K, Park LY, Zucker RA (2007) Genotype and neutopsychological response inhibition as resilience promotors for ADHD, OCD, and CD under conditions of psychosocial adversity. Dev Psychopathol. 19:767-786.

Noll DC (2002) Rapid MR image acquisition in the presence of background gradients, Paper Presented at the IEEE International Symposium on Biomedical Imaging, Washington, DC.

Oppenheim A, Schafer R (1989) Discrete-Time Signal Processing. Prentice Hall, Englewood Cliffs, NJ.

Phan KL, Fitzgerald DA, Nathan PJ, Moore GJ, Uhde TW, Tancer ME (2005) Neural substrates for voluntary suppression of negative affect: a functional magnetic resonance imaging study. Biol Psychiatry 57:210-219.

Phan KL, Wager T, Taylor SF, Liberzon I (2002) Functional neuroanatomy of emotion: a meta-analysis of emotion activation studies in PET and fMRI. Neuroimage 16:331-348.

Piazza PV, Rouge-Pont F, Deminiere JM, Kharoubi M, Le Moal M, Simon H (1991) Dopaminergic activity is reduced in the prefrontal cortex and increased in the nucleus accumbens of rats predisposed to develop amphetamine self-administration. Brain Res 567:169-174.

Rohde P, Lewinsohn PM, Seeley JR (1996) Psychiatric comorbidity with problematic alcohol use in high school students. J Am Acad Child Adolesc Psychiatry 35:101-109.
Rolls ET (2004) The functions of the orbitofrontal cortex. Brain Cogn 55:1129.

Russell M (1990) Prevalence of alcoholism among children of alcoholics, in Children of Alcoholics: Critical Perspectives (Windle M, Searles J eds), pp 9-38. Guilford Press, New York.

Schweinsburg AD, Paulus MP, Barlett VC, Killeen LA, Caldwell LC, Pulido C, Brown SA, Tapert SF (2004) An FMRI study of response inhibition in youths with a family history of alcoholism. Ann N Y Acad Sci 1021:391-394.

Sher KJ (1993) Children of alcoholics: A critical appraisal of theory and research. Psychol Addict Behav 7:201-202.

Slutske WS, Heath AC, Madden PA, Bucholz KK, Statham DJ, Martin NG (2002) Personality and the genetic risk for alcohol dependence. J Abnorm Psychol 111:124-133.

Sutton BP, Noll DC, Fessler JA (2002) Field-corrected imaging using joint estimation of image and field map, Paper Presented at the 10th Scientific Meeting of the International Society for Magnetic Resonance in Medicine, Honolulu, HI.

Sutton BP, Noll DC, Fessler JA (2003) Fast, iterative image reconstruction for MRI in the presence of field inhomogeneities. IEEE Trans Med Imaging 22:178-188.

Tapert SF, Brown GG, Kindermann SS, Cheung EH, Frank LR, Brown SA (2001) fMRI measurement of brain dysfunction in alcohol-dependent young women. Alcohol Clin Exp Res 25:236-245.

Volkow ND, Fowler JS, Wang GJ (2004) The addicted human brain viewed in the light of imaging studies: brain circuits and treatment strategies. Neuropharmacology 47(Suppl. 1):3-13.

Volkow ND, Wang GJ, Begleiter H, Porjesz B, Fowler JS, Telang F, Wong C, Ma Y, Logan J, Goldstein R, Alexoff D, Thanos PK (2006) High levels of dopamine D2 receptors in unaffected members of alcoholic families: possible protective factors. Arch Gen Psychiatry 63:999-1008.

Volkow ND, Wang GJ, Fowler JS, Logan J, Hitzemann R, Ding YS, Pappas N, Shea C, Piscani K (1996) Decreases in dopamine receptors but not in dopamine transporters in alcoholics. Alcohol Clin Exp Res 20:1594-1598.

Volkow ND, Wang GJ, Maynard L, Fowler JS, Jayne B, Telang F, Logan J, Ding YS, Gatley SJ, Hitzemann R, Wong C, Pappas N (2002) Effects of alcohol detoxification on dopamine D2 receptors in alcoholics: a preliminary study. Psychiatry Res 116:163-172.

White HR, Xie M, Thompson W, Loeber R, Stouthamer-Loeber M (2001) Psychopathology as a predictor of adolescent drug use trajectories. Psychol Addict Behav 15:210-218.

Wills TA, Vaccaro D, McNamara G, Hirky AE (1996) Escalated substance use: a longitudinal grouping analysis from early to middle adolescence. J Abnorm Psychol 105:166-180.

Wong MM, Zucker RA, Puttler LI, Fitzgerald HE (1999) Heterogeneity of risk aggregation for alcohol problems between early and middle childhood: nesting structure variations. Dev Psychopathol 11:727-744.

Zucker R (1994) Pathways to alcohol problems and alcoholism: A developmental account of the evidence for multiple alcoholism and for contextual contributions to risk, in The Development of Alcohol Problems: Exploring the Biopsychosocial Matrix of Risk (Zucker R, Boyd G, Howard J eds). NIAAA, Rockville, MD.

Zucker RA (2006) Alcohol use and alcohol use disorders: A developmentalbiopsychosocial systems formulation covering the life course, in Developmental Psychopathology: Vol 3 Risk, Disorder and Adaptation, 2nd edn., (Cicchetti D, Cohen DJ eds), pp 620-656. Wiley \& Sons, Hoboken, NJ.

Zucker RA, Fitzgerald HE (1994) Drinking and Drug History Form for Children. University of Michigan Department of Psychiatry, Addiction Research Center, Ann Arbor.

Zucker RA, Fitzgerald HE, Moses HD (1995) Emergence of alcohol problems and the several alcoholisms: A developmental prospective on etiologic theory and life course trajectory, in Developmental Psychopathology: Vol. 2 Risk, Disorder, and Adaptation (Cicchetti D, Cohen DDJ eds), pp 677-711. Wiley, New York.

Zucker R, Fitzgerald H, Noll R (1990), Drinking and Drug History, (Revised edition, Version 4). University of Michigan Department of Psychiatry, Addiction Research Center, Ann Arbor. 
Zucker RA, Fitzgerald HE, Refior SK, Puttler LI, Pallas DM, Ellis DA (2000) The clinical and social ecology of childhood for children of alcoholics: Description of a study and implications for a differentiated social policy, in Children of Addiction: Research, Health and Policy Issues (Fitzgerald HE, Lester BM, Zucker RA eds), pp 109-141. Routledge Falmer, New York.
Zucker R, Wong M, Puttler L, Fitzgerald H (2003) Resilience and Vulnerability Among Sons of Alcoholics: Relationship to Developmental Outcomes Between Early Childhood and Adolescence, in Resilience and vulnerability: Adaptation in the context of childhood adversities (Luthar S ed), pp 76-103. Cambridge University Press, New York. 